\title{
LC-MS and LC-PDA Analysis of Hypericum empetrifolium and Hypericum sinaicum
}

\author{
Feras Q. Alali ${ }^{\mathrm{a} *}$, Khaled Tawaha ${ }^{\mathrm{b}}$, and Mohammad Gharaibeh ${ }^{\mathrm{c}}$
}

a Department of Pharmaceutical Chemistry, Faculty of Pharmacy, Al Isra Private

University, P. O. Box 22, 33, Amman 11622, Jordan. E-mail: falali@isra.edu.jo

b Department of Pharmaceutical Sciences, Faculty of Pharmacy, University of Jordan, Amman 11942, Jordan

c Department of Natural Resources and Environment, Faculty of Agriculture, Jordan University of Science and Technology, P. O. Box 3030, Irbid 22110, Jordan

* Author for correspondence and reprint requests

Z. Naturforsch. 64c, 476-482 (2009); received February 25/March 26, 2009

Within the framework of our continuous efforts to explore Hypericum species from Jordan, we report the analysis of the major active metabolites, naphthodianthrones and phloroglucinols, in the methanolic extracts of two under-explored Hypericum species; H. empetrifolium Willd. and H. sinaicum Hochst. \& Steud. ex Boiss., using LC-(+,-)-ESI-MS (TIC and SIM) and LC-UV/Vis spectroscopy. Based on their LC-UV/Vis profiles, retention times and $(+,-)$-ESI-MS (TIC and SIM) spectral data, hypericin, protohypericin and pseudohypericin were identified in both of the investigated species. In addition adhyperfirin was only detected in H. empetrifolium, while hyperforin and protopseudohypericin were only detected in H. sinaicum. This is the first report documenting the presence of hypericin, protohypericin, pseudohypericin, protopseudohypericin, and hyperforin in $H$. sinaicum, and adhyperfirin in H. empetrifolium.

Key words: Hypericum, Naphthodianthrones, Phloroglucinols

\section{Introduction}

Hypericum is a genus of about 450 species of herbs or shrubs belonging to the family Clusiaceae, formerly Hypericaceae. The genus grows widely in temperate regions, and is used in traditional medicinal practices in various parts of the world. All members of the genus may be referred to as "Saint John' wort", though they are also commonly just called Hypericums; other names include "Rose of Sharon" and "Tutsan" (Anonymous, 2007; Robson, 1990, 2003; Yazaki and Okada, 1994). The plant specimen records at National Center for Agricultural Research and Extension (NCARE), Ministry of Agriculture, Baq'a, Jordan, showed the presence of seven species of $\mathrm{Hy}$ pericum in Palestine flora during 1900-1910. In his list of wild plants in Jordan, Al-Eisawi (1998) reported the presence of 5 species of Hypericum; $H$. hyssopifolium Chaix, $H$. languinosum Lam., $H$. olivieri (Spach) Boiss. H. serpyllifolium Lam., and H. triquetrifolium Turra. Danin (1997) discovered a population of $H$. sinaicum Hochst. \& Steud. ex Boiss. in Jordan at Dana Nature Reserve. Most species of Hypericum can be identified by: (i) opposite simple entire exstipulate leaves containing translucent and often black or red glandular secretions; (ii) flowers with a 5-merous perianth comprising green (sometimes red-tinged) sepals and free yellow (often red-tinged) petals, stamens in 3-5 bundles or fascicles, and an ovary with 3-5 slender styles; and (iii) a capsular fruit containing many small cylindrical seeds (Robson, 2003).

One of the most important and commercially recognized species of the genus Hypericum is $H$. perforatum, commonly known as St. John's wort. The antidepressant activity of this species is the cause for the widespread interest in the study of the Hypericum genus (Hu and Sim, 2000). H. perforatum L. is well known for its profound pharmacological activities as mild antidepressant, anxiolytic, antiviral, wound healing and antimicrobial agent (Barnes et al., 2001; Butterweck et al., 2002; Sakar and Tamer, 1990). Prescribed as mild antidepressant therapeutic, commercially available products of $H$. perforatum are among the best selling, most successful and effective herbs in the world. 
The Hypericum genus is rich in secondary metabolites, many of which are biologically active. Of the main constituents are naphthodianthrones (hypericin, pseudohypericin, protohypericin, and protopseudohypericin), phloroglucinols (hyperforin, adhyperforin, hyperfirin, and adhyperfirin), and a broad range of flavonoids (e.g., hyperoside and rutin) (Nahrstedt and Butterweck, 1997). The antidepressant activity of $H$. perforatum was first attributed to the naphthodianthrones. Recent studies revealed that the phloroglucinol hyperforin and its derivative adhyperforin inhibit various neurotransmitter receptors (Butterweck et al., 2001; Chatterjee et al., 1998; Laakmann et al., 1998; Meruelo et al., 1988; Muller et al., 1998, 2001).

The objective of the present study was to investigate, at the analytical level, the methanolic extracts of two unexplored Hypericum species of Jordanian origin, namely $H$. empetrifolium Willd. and H. sinaicum Hochst. \& Steud. ex Boiss., for their major secondary metabolites, mainly phloroglucinols and naphthodianthrones using liquid chromatography-electrospray mass spectrometry and liquid chromatography-UV spectroscopy [LC-(+,-)-ESI-MS (total ion chromatograms, TIC, and selected ion monitoring, SIM) and LCUV]. Although there were limited preliminary phytochemical and analytical studies, none of the abovementioned species has been investigated previously for bioactive constituents using LCESI-MS and LC-UV/PDA (Crockett et al., 2007; Kitanov, 2001; Rezanka and Sigler, 2007; Xenophontos et al., 2007).

$H$. empetrifolium and $H$. sinaicum grow wild in the northern part of Jordan at Ramtha, Ajloun and Irbid. $H$. sinaicum is $10-30 \mathrm{~cm}$ high, altogether slightly pubescent. Flowers are few in a terminal corymbose panicle. The plant is toxic to livestock (Batanouny, 1999). H. empetrifolium, also called Dwarf Hypericum, has deep yellow flowers in late spring to early summer (Batanouny, 1999).

Based on their UV profiles, retention times and $(+,-)$-ESI (TIC and SIM) mass spectral data, hypericin, protohypericin and pseudohypericin were identified in both of the investigated Hypericum species; while adhyperfirin was only detected in H. empetrifolium, hyperforin and protopseudohypericin were only detected in $H$. sinaicum. This is the first report documenting the presence of hypericin, protohypericin, pseudohypericin, protopseudohypericin, and hyperforin in H. sinaicum, and adhyperfirin in H. empetrifolium.

\section{Results and Discussion}

The investigation benefitted from the available literature on spectral data and chromatographic elution patterns of phloroglucinols and naphthodianthrones (Fuzzati et al., 2001; Tolonen et al., 2002; Wolfender et al., 2003). Thus, LC-(+,-)ESI-MS (TIC and SIM) and LC-UV data were utilized in an integrative manner to confirm the identity of these compounds in the crude methanolic extracts.

A hypericin reference standard was used to develop the optimum chromatographic separation conditions. A neutral mobile phase was used to able the switch between the positive and negative ionization modes simultaneously. The conditions were optimized for resolution and response as outlined in the experimental section. The total run time was $35 \mathrm{~min}$, with a retention time of $16.1 \mathrm{~min}$ for hypericin.

The methanolic extract of the total aerial parts of $H$. empetrifolium and $H$. sinaicum were analyzed for the presence of phloroglucinols (hyperforin, adhyperforin, hyperfirin, and adhyperfirin) and naphthodianthrones (hypericin, pseudohypericin, protohypericin, and protopseudohypericin) using LC-ESI-MS and LC-UV. LC-MS full scan TICs, scanning $m / z, 50-1000$, were first acquired in both positive and negative ionization modes. This was followed by positive and negative SIM analyses. SIM was utilized in compounds' detection in order to overcome the low sensitivity of the TIC observed. The following naphthodianthrone molecular ions, $[\mathrm{M}-\mathrm{H}]^{-}$, were monitored in the negative ionization mode: hypericin, $\mathrm{m} / \mathrm{z}$ 503; pseudohypericin, $\mathrm{m} / \mathrm{z} 519$; protohypericin, $\mathrm{m} / z$ 505; and protopseudohypericin, $\mathrm{m} / z$ 521. The negative ionization mode was found to be highly sensitive for this class of phenolic compounds. On the other hand, the positive ionization SIM mode was used to monitor the following phloroglucinol molecular ions, $[\mathrm{M}+\mathrm{H}]^{+}$: hyperforin; $\mathrm{m} / \mathrm{z}$ 537; adhyperforin, $\mathrm{m} / \mathrm{z}$ 551; hyperfirin, $\mathrm{m} / \mathrm{z}$ 469; and adhyperfirin, $m / z$ 483. Compared to TIC, the SIM sensitivity was significantly higher for both investigated chemical classes. Fig. 1 shows typical stacked (+,-)-ESI LC-MS TIC chromatograms of the methanolic extracts of the aerial parts of $H$. empetrifolium and $H$. sinaicum. Table I summarizes the retention times, $\mathrm{UV}_{\max }$ data, and the molecular ions of the identified compounds. By analyzing the LC-UV and mass spectral data and by 

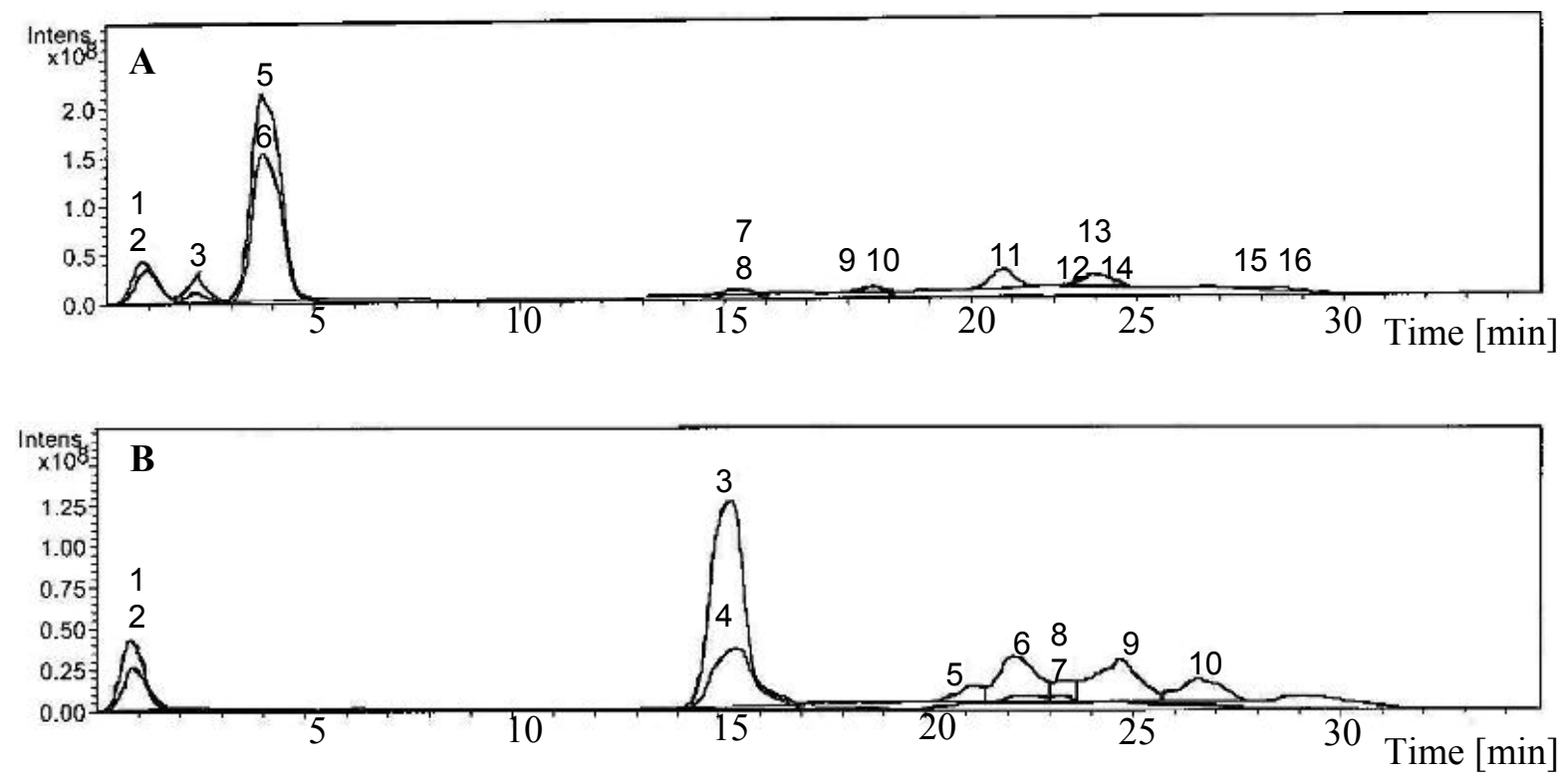

Fig. 1. Stacked (+,-)-ESI TIC chromatograms of (A) H. empetrifolium and (B) H. sinaicum.

Table I. Retention times and mass spectral data of the (+)- and (-)-ESI TIC and (+)- and (-)-SIM chromatographic peaks.

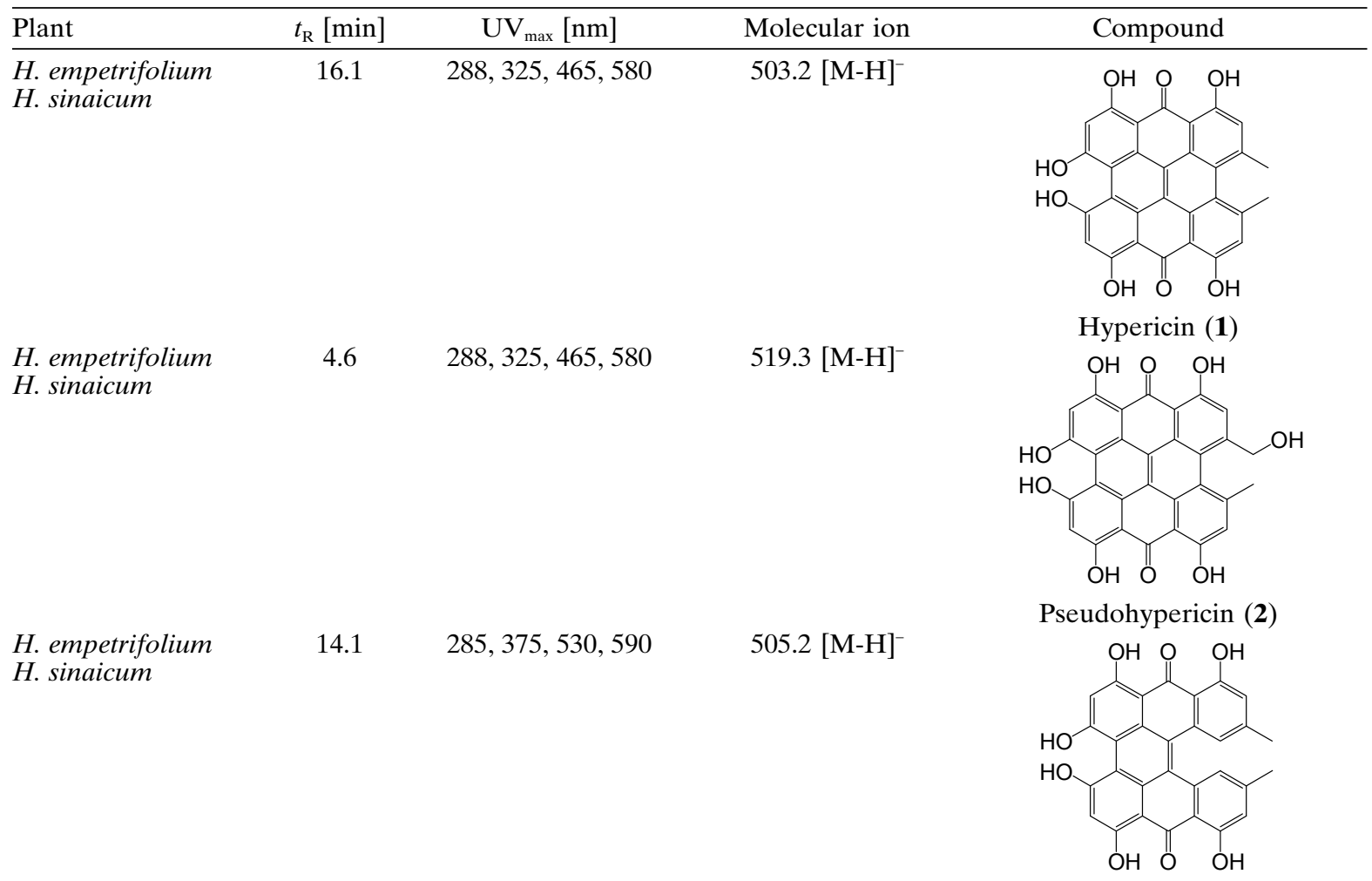

Protohypericin (3) 


\begin{tabular}{lccccc}
\hline Plant & $t_{\mathrm{R}}[\mathrm{min}]$ & $\mathrm{UV}_{\max }[\mathrm{nm}]$ & Molecular ion \\
\hline H. sinaicum & 3.2 & $285,375,550$ & $521.3[\mathrm{M}-\mathrm{H}]^{-}$ \\
H. sinaicum & 285 & \\
H. empetrifolium & &
\end{tabular}

comparison with those reported in the literature, hypericin (1), pseudohypericin (2), protohypericin (3), protopseudohypericin (4), and hyperforin (5) were tentatively identified in H. sinaicum. Hypericin (1), pseudohypericin (2), protohypericin (3), and adhyperfirin (6) were identified in H. empetrifolium.

The (-)-ESI mass spectra of hypericin (1) $\left(t_{\mathrm{R}}=\right.$ $16.1 \mathrm{~min}$ ) from $H$. empetrifolium and $H$. sinaicum showed a parent molecular ion at $\mathrm{m} / z$ 503.2 [M$\mathrm{H}]^{-}$. The UV spectrum of hypericin showed four absorption maxima at 288, 325, 465 and $580 \mathrm{~nm}$, which are typical values for hypericin providing an additional proof for the identity of this compound (Brolis et al., 1998; Liu et al., 2000; Mauri and Pietta, 2000; Tolonen et al., 2002, 2003). The identity of this compound was verified by comparison of its ESI mass spectrum, UV spectrum, and the HPLC retention time with an authentic standard of hypericin, where complete matching was observed.

The (-)-ESI mass spectra of $H$. empetrifolium and $H$. sinaicum showed also parent molecular ions at $\mathrm{m} / z$ 519.3 [M-H] $]^{-}$and an identical UV spectrum with that of hypericin, but eluted at an earlier time $\left(t_{\mathrm{R}}=4.6 \mathrm{~min}\right)$, i.e. this compound is more polar. These spectral data suggest the identity of this compound as pseudohypericin (2) (Brolis et al., 1998; Liu et al., 2000; Mauri and Pietta, 2000; Tolonen et al., 2003).

The (-)-ESI mass spectrum of the peak at $t_{\mathrm{R}}=$ $14.1 \mathrm{~min}$, from $H$. empetrifolium and $H$. sinaicum, showed a parent molecular ion at $\mathrm{m} / \mathrm{z}$ 505.2 [M$\mathrm{H}]^{-}$, i.e. $2 \mathrm{Da}$ more than the analogous peak in hypericin; it was also eluted at an earlier retention time than hypericin. The UV spectrum of the compound showed the following absorption maxima 285, 375, 530, and $590 \mathrm{~nm}$. These data 
suggested that this compound was protohypericin (3) (Tolonen et al., 2003).

The (-)-ESI mass spectrum of the peak at $t_{\mathrm{R}}=$ $3.2 \mathrm{~min}$ of $H$. sinaicum showed a parent molecular ion at $m / z 521.3$ for $[\mathrm{M}-\mathrm{H}]^{-}, 2 \mathrm{Da}$ more than the analogous peak in pseudohypericin; it was also eluted at an earlier retention time than pseudohypericin. The UV spectrum of the compound showed absorption maxima at 285, 375, and $550 \mathrm{~nm}$. These data suggested that this compound was protopseudohypericin (4) (Tolonen et al., 2003).

In $H$. sinaicum, the (-)- and (+)-ESI mass spectra of the peaks at $t_{\mathrm{R}}=15.3 \mathrm{~min}$ showed parent molecular ions of 537.6 and 535.6 for $[\mathrm{M}+\mathrm{H}]^{+}$and $[\mathrm{M}-\mathrm{H}]^{-}$, in the positive and negative ionization modes, respectively. The UV spectrum showed an absorption maximum at $285 \mathrm{~nm}$, characteristic of phloroglucinols. These mass spectral data suggested that this compound was hyperforin (5) (Tolonen et al., 2003).

Finally, the (+)-ESI mass spectrum of the peak at $t_{\mathrm{R}}=18.7 \mathrm{~min}$, in $H$. empetrifolium, showed a parent molecular ion at $\mathrm{m} / \mathrm{z} \quad 483.3$ for $[\mathrm{M}+\mathrm{H}]^{+}$, while the UV spectrum showed an absorption maximum at $285 \mathrm{~nm}$ suggesting that the compound was adhyperfirin (6).

Importantly, there were several other peaks in the (-)- and (+)-ESI TIC mass spectra of $H$. empetrifolium and $H$. sinaicum that based on their molecular ions, and UV spectra could not be identified or dereplicated to any obvious structural class reported in the literature for the genus Hypericum. These could be potentially new compounds; hence our future efforts will be focused toward their classification and identification.

In summary, we have developed a new strategy identify of the major secondary metabolites (phloroglucinols and naphthodianthrones) in $H$. empetrifolium and $H$. sinaicum based on integrating data from LC-UV/PDA (distinctive UV spectra for different classes), LC-ESI-MS $[(+,-)$-TIC and (+,-)-SIM) $]$ and chromatographic elution patterns. We were able to identify five major compounds; hypericin (1), pseudohypericin (2), protohypericin (3), and protopseudohypericin (4), and hyperforin (5) in $H$. sinaicum, while in H. empetrifolium four compounds were identified, hypericin (1), pseudohypericin (2), protohypericin (3), and adhyperfirin (6). This is the first report on the presence of hypericin, protohypericin, pseudohypericin, protopseudohypericin, and hyperforin in $H$. sinaicum. The literature only reports the presence of sinaicinone, a complex adamantanyl derivative, in $H$. sinaicum (Rezanka and Sigler, 2007). Regarding H. empetrifolium, this is the first report documenting the presence of adhyperfirin. The presence of pseudohypericin in H. empetrifolium was found to be in agreement with an earlier study (Xenophontos et al., 2007). Our study adds to the study of Kitanov (2001) in which H. empetrifolium was among 36 species of Hypericum evaluated for their hypericin and pseudohypericin content where only hypericin was found in H. empetrifolium.

\section{Experimental}

\section{General}

LC-MS data were determined using an Agilant ${ }^{\circledR}$ (Palo Alto, CA, USA) ion-trap mass spectrometer equipped with an electrospray ionization source and an Agilant ${ }^{\circledR} 100$ series HPLC instrument. The separation was achieved using a Hypersil ODS $(125 \mathrm{~mm} \times 4 \mathrm{~mm} ; 5 \mu \mathrm{m})$ column (Thermo Electron, Auchtermuchty, UK). The mobile phases used were: (A) $20 \mathrm{~mm}$ ammonium acetate; (B) acetonitrile. The flow rate was $1 \mathrm{~mL} / \mathrm{min}$ in the following gradient system: $0-10 \mathrm{~min}, 50 \%$ B; $10-25 \mathrm{~min}, 90 \% \mathrm{~B} ; 30-35 \mathrm{~min} 50 \% \mathrm{~B}$. The injection volume was $20 \mu \mathrm{L}$, and the total run time was $35 \mathrm{~min}$. The mass detector conditions were set as follows: ESI positive and negative ionization modes; full scan mode from 50 to $1000 \mathrm{~m} / z$; capillary voltage, $4000 \mathrm{~V}$; ESI temperature, $325^{\circ} \mathrm{C}$; gas flow rate, $5 \mathrm{~L} / \mathrm{min}$.

LC-UV/Vis spectra were obtained on a Lachrom $^{\circledR}$ Merck-Hitachi (Tokyo, Japan) HPLC instrument, equipped with a quaternary gradient L-7150 pump, L-7455 photodiode-array (PDA) detector, L-7200 auto-sampler, and D-7000 interface in the range $250-650 \mathrm{~nm}$. Mobile phase, flow rate, analytical column, injection volume, and run times were identical to those for LC-MS.

Ammonium acetate (extra pure) was obtained from Scharlau Chemie S.A. (Barcelona, Spain), methanol (HPLC grade) was obtained from Tedia Company Inc. (Fairfield, OH, USA), acetonitrile (HPLC grade) was obtained from LEDA, Scharlau Chemie S.A., and (-)-hypericin (standard) was purchased from Sigma-Aldrich (Buchs, Switzerland). 


\section{Plant material}

H. empetrifolium and H. sinaicum were collected from Ajloun Nature Reserve, Northern part of Jordan during their flowering stage in 2007. The collected materials were identified by $\mathrm{M}$. G. The raw plant materials were cleaned and air-dried at room temperature, then ground to a fine powder using a blender (Moulinex ${ }^{\circledR}$, Caen, France), passed through a 24-mesh sieve to generate a homogeneous powder, stored at room temperature $\left(22-23^{\circ} \mathrm{C}\right)$, and protected from light until required for analyses.

\section{Samples preparation and analysis}

From each finely ground plant material, $(1000 \pm 0.1) \mathrm{mg}$ were accurately weighed, placed in a $250-\mathrm{mL}$ round bottom flask fitted with a reflux condenser, and refluxed for $20 \mathrm{~min}$ using $80 \mathrm{~mL}$ of HPLC methanol. The samples were then filtered, saving the filtrate. The herb materials were re-extracted twice with $60 \mathrm{~mL}$ HPLC methanol, followed each time by filtration. The collected filtrates and washes were combined. The volume was reduced to a final volume of about $3 \mathrm{~mL}$ us-

Al-Eisawi D. M. (1998), Field Guide to Wild Flowers of Jordan and Neighbouring Countries. Jordan Press Foundation, Al-Rai, Amman, pp. 1-12.

Anonymous (2000), INA Methods Validation Program. Determination of hypericin and pseudohypericin in St. John's wort by high performance liquid chromatography. 107.000. Institute for Nutraceutical Advancement, Denver, CO, USA, pp. 1-4.

Anonymous (2007), Hypericum. Available from: http:// en.wikipedia.org/wiki/Hypericum

Barnes J., Anderson L., and Phillipson J. (2001), St. John wort (Hypericum perforatum L.): a review of its chemistry pharmacology and clinical properties. J. Pharm. Pharmacol. 53, 583-600.

Batanouny K. H. (1999), Wild Medicinal Plants in Egypt. Academy of Scientific Research and Technology, Cairo, Egypt, Chapter 4, pp. 1-10.

Brolis M., Gabetta B., Fuzzati N., Pace R., Panzeri F., and Peterlongo F. (1998), Identification by high-performance liquid chromatography-diode array detection-mass spectrometry and quantification by highperformance liquid chromatography-UV absorbance detection of active constituents of Hypericum perforatum. J. Chromatogr. A 825, 9-16.

Butterweck V., Korte B., and Winterhoff H. (2001), Pharmacological and endocrine effects of Hypericum perforatum and hypericin after repeated treatment. Pharmacopsychiatry 34S, 2-7. ing a rotary evaporator (RE 200, Bibby Steriline Ltd., Stone, UK). The concentrated solutions were transferred to a $25-\mathrm{mL}$ flask and diluted to volume using methanol. Aliquots were removed and centrifuged at $4500 \mathrm{rpm}$ for $5 \mathrm{~min}$ using an EBA 20 centrifuge (Hettich-Zentrifugen $\mathrm{GmbH}$ \& Co. KG, Tuttlingen, Germany). Supernatants were transferred into glass vials and stored in a refrigerator until required for analysis (Anonymous, 2000).

For the LC-MS and LC-UV studies, aliquots of the supernatants of the methanolic extracts of each plant were filtered through a $0.45-\mu \mathrm{m} \mathrm{Te}-$ flon filter and then transferred into 2-mL amber HPLC vials. A $20-\mu \mathrm{L}$ aliquot was injected. Hypericin standard was used for retention time matching.

\section{Acknowledgements}

The authors acknowledge the financial support from the Deanship of Scientific Research, JUST, Irbid, Jordan and the technical help of Mr. Munther Tahtamoni, Princess Haya Biotechnology Center and Ms. Tamam El-Elimat, Pharmaceutical Research Center, JUST, Jordan.

Butterweck V., Bockers T., Korte B., Wittkowski W., and Winterhoff H. (2002), Long-term effects of St. John's wort and hypericin on monoamine levels in rat hypothalamus and hippocampus. Brain Res. 930, $21-29$

Chatterjee S. S., Bhattacharya S. K., Wonnemann M., Singer A., and Muller W. E. (1998), Hyperforin as a possible anti-depressant component of Hypericum extracts. Life Sci. 63, 499-510.

Crockett S., Kunert O., and Bauer R. (2007), Phloroglucinol derivatives from two Mediterranean Hypericum L. (Clusiaceae) species. Planta Med. 73, DOI: 10.1055/s-2007-987206.

Danin A. (1997), Contributions to the flora of Jordan: new and interesting plants from Dana Nature Reserve, SW Jordan. Willdenowia 27, 161-175.

Fuzzati N., Gabetta G., Streponi I., and Villa F. (2001), High performance liquid chromatography-electrospray ionisation mass spectrometry and multiple mass spectrometry studies of hyperforin degradation products. J. Chromatogr. A 926, 187-198.

Hu L. and Sim K. (2000), Sampsoniones A-M, a unique family of caged polyprenylated benzoylphloroglucinol derivatives, from Hypericum sampsonii. Tetrahedron 56, 1379-1386.

Kitanov G. M. (2001), Hypericin and pseudohypericin in some Hypericum species. Biochem. Syst. Ecol. 29, $171-178$. 
Laakmann G., Schule C., Baghai T., and Kieser M. (1998), St. John's wort in mild to moderate depression: the relevance of hyperforin for the clinical efficacy. Pharmacopsychiatry 31, 54-59.

Liu F. F., Ang C. Y. W., Heinze T. M., Rankin J. D., Beger R. D., Freeman J. P., and Lay Jr J. O. (2000), Evaluation of major active components in St. John's wort dietary supplements by high performance liquid chromatography with photodiode array detection and electrospray mass spectrometric confirmation. J. Chromatogr. A 888, 85-92.

Mauri P. and Pietta P. (2000), High performance liquid chromatography/electrospray mass spectrometry of Hypericum perforatum extracts. Rapid Commun. Mass Spectrom. 14, 95-99.

Meruelo D., Lavie G., and Lavie D. (1988), Therapeutic agents with dramatic antiretroviral activity and little toxicity at effective doses: aromatic polycyclic diones hypericin and pseudohypericin. Proc. Natl. Acad. Sci. USA 85, 5230-5234.

Muller W. E., Singer A., Wonnemann M., Hafner U., Rolli M., and Schafer C. (1998), Hyperforin represents the neurotransmitter reuptake inhibiting constituent of Hypericum extract. Pharmacopsychiatry 31S, 16-21.

Muller W. E., Singer A., and Wonnemann M. (2001), Hyperforin anti-depressant activity by a novel mechanism of action. Pharmacopsychiatry 34S, 98-102.

Nahrstedt A. and Butterweck V. (1997), Biologically active and other chemical constituents of the herb Hypericum perforatum L. Pharmacopsychiatry 30 (Suppl.), 129-134.

Rezanka T. and Sigler K. (2007), Sinaicinone, a complex adamantanyl derivative from Hypericum sinaicum. Phytochemistry 68, 1272-1276.
Robson N. (1990), Studies in the genus Hypericum L. (Guttiferae) 8. Section 29, Brathys (part 2), and 30, Trigynobrathys. Bull. Brit. Nat. Hist. Mus. (Bot.) 20, $1-151$.

Robson N. (2003), Hypericum botany. In: Hypericum: The Genus Hypericum (Ernst E., ed.). Taylor and Francis, New York, pp. 196-241.

Sakar M. and Tamer A. (1990), Antimicrobial activity of different extracts from Hypericum species. Fitoterapia 61, 464-466.

Tolonen A., Uusitalo A., Hohtola J., and Jalonen J. (2002), Determination of naphthodianthrones and phloroglucinols from Hypericum perforatum extracts by liquid chromatography/tandem mass spectrometry. Rapid Commun. Mass Spectrom. 16, 396-402.

Tolonen A., Hohtola A., and Jalonen J. (2003), Fast HPLC/PDA analysis of naphthodianthrones and phloroglucinols from Hypericum perforatum extracts. Phytochem. Anal. 14, 306-309.

Wolfender J. L., Verotta L., Belvisi L., Fuzzati N., and Hostettmann K. (2003), Structural investigations of isomeric oxidised forms of hyperforin by HPLC-NMR and HPLC-MSn. Phytochem. Anal. 14, 290-297.

Xenophontos M., Stavropoulos E., Avramakis E., Navakoudis E., Dörnemann D., and Kotzabasis K. (2007), Influence of the developmental stage on the (proto)hypericin and (proto)pseudohypericin levels of Hypericum plants from Crete. Planta Med. 73, 1309-1315.

Yazaki K. and Okada T. (1994), Hypericum erectum Thunb. (St. John's wort): in vitro culture and the production of procynadins. Biotechnol. Agric. Forest. 26, $167-178$. 